\title{
Innovative Work Environment, Internal Locus of Control and Intrinsic Job Satisfaction: Evidence from Bangladeshi Employees
}

\author{
Mohammad Tareq, $\mathrm{PhD}^{1} \quad$ Abdullah Al Mahmud, $\mathrm{PhD}^{2 *} \quad$ Sejuti Rahman, $\mathrm{PhD}^{3}$ \\ 1.Associate Professor, Department of Accounting and Information Systems, University of Dhaka, Bangladesh \\ 2.Associate Professor, Department of Banking \& Insurance, University of Dhaka, Bangladesh \\ 3.Assistant Professor, Department of Robotics and Mechatronics Engineering, University of Dhaka, Bangladesh
}

\begin{abstract}
Pecuniary reward and perquisites can satisfy employees extrinsically; however, employees become intrinsically satisfied if they are offered challenge and autonomy in their jobs. Thus, jobs can be tailored to increase workers' intrinsic job satisfaction. Moreover, if employees of an organization are given an innovative work environment, then it can satisfy them intrinsically as well. A workplace is innovative if it allows employees to take new initiatives, to change the existing systems, and to do jobs in a new way that is more efficient than the existing one. However, these phenomena are related to employees with a high internal locus of control, a personality trait desirable to employers in many jobs. Given these theoretical backdrops, this paper studies the influence of innovative work environments on intrinsic job satisfaction of employees in Bangladeshi organizations. Data were collected from 304 employees working in Bangladeshi organizations to investigate these. The contribution of this paper is that the finding of this study can give deep insight and thus help them framing organizational policy and recruitment policy.
\end{abstract}

Keywords: Intrinsic Satisfaction, Innovative Environment, Internal Locus of Control, Personality Trait

JEL Classification: D23

DOI: $10.7176 / \mathrm{EJBM} / 12-29-05$

Publication date:October $31^{\text {st }} 2020$

\section{Introduction}

Intrinsically satisfied employees consistently display high levels of creativity and resilience at failure and conscientious at work. Past research shows that intrinsically satisfied employees perform better than intrinsically less satisfied employees. Results of the meta-analysis by Kinicki et al. (2002) and Iaffaldano and Muchinsky (1985) found that intrinsic job satisfaction (IJS hereafter) is positively related to job performance $\rho=.27$ and $\rho=.23$ respectively. The result of the study of Kinicki et al. (2002) also showed that IJS is negatively related to withdrawal cognition and different withdrawal behavior, for example, intention to leave the organization $(\rho=-.50)$, lateness $(\rho=-.22)$, turnover $(\rho=-.30)$, etc. Employees are vital resources for organizations. Therefore, a reduction in employees' performance causes huge losses to organizations. Moreover, employees' withdrawal behavior can cause direct and indirect financial loss to organizations. Sagie et al. (2002, p.74) have identified four type of costs related to employee withdrawal behavior: decrease of revenues due to work undone; an indirect cost coming from the negative effects of worker's withdrawal behavior on colleagues and co-workers; the cost of the potential progression to further and more acute problem due to the withdrawal behaviors. Cost of hiring and training a new employee if the withdrawal behavior turns into employees leaving the organization permanently. Therefore, IJS is a critical factor for organizations. Organizations can satisfy employees intrinsically by rewarding their employees through challenging and more autonomy at work.

The Job Characteristic Theory of Hackman and Oldham suggests that organizations can enrich jobs by encouraging their workers to take on more responsibility for planning, coordinating, and managing their work. The central premise of the approach to job enrichment is the idea that jobs can be customized to increase IJS among employees. Besides giving the employees autonomy, if a creative work environment is provided to employees, it can increase their IJS. Employees are encouraged to take new approaches in an creative work environment, change the current processes, and do jobs in a different way that is more effective than the old one. Thus, an innovative work environment gives employees opportunities to use their creativity that in turn makes them feel intrinsically satisfied.

The idea that job characteristics and/or innovative work environments affect an individual's IJS is a situationist view. Unlike the situationist 's view, there is a view that IJS originates from something beyond or beyond a person's inner component. The personologists, supporters of this view, would argue that IJS is primarily defined by the individuality 's internal characteristics, which are relatively stable over time and consistent across contexts. Personologists have established a number of work satisfaction-related characteristics over the last two decades for example, the Internal Locus of Control (ILC hereafter) has been identified as highly related to satisfaction (see, $\mathrm{Ng}$ et al., 2006).

Though the past research has made an important contribution to the IJS literature, questions that have not received considerable attention and, therefore, remain untested are: (1) how innovative work environment and ILC 
can cause IJS? (2) whether the influence of ILC on IJS is increased in an innovative environment? In this paper, the researcher studies the direct effect of ILC on IJS, the mediation effect of innovative work environment on the relationship between ILC and IJS, and the interaction effect of the innovative work environment and ILC on IJS.

\section{Literature Review and Proposed Model 2.1 ILC and IJS}

A psychological construct, locus of control, was developed by Julian B. Rotter in 1954 as an important aspect of personality. It refers to one's belief on what causes good or bad results in his/her life. If one believes that a good result of his/her action depends on his/her ability, then that person is high on ILC. According to the perception mechanism (Spector et al., 2000) traits act as a filter that shapes one's perception of the world. Hence, people with some traits negatively see the world, and others see it positively. People with high ILC see outcomes as the results of their actions, and if they get successful, they become intrinsically satisfied as they think that this success is the manifestation of their ability. Past research has consistently found that people with high ILC are more satisfied at work. Judge and Bono (2001) observe that ILC is related to job satisfaction. Ng et al. (2006) in their meta-analytic study finds that locus of control significantly influences employees' job satisfaction. The researchers are not aware of any notable study that investigated the relationship between ILC and IJS except one notable exception of Tareq and Watanabe (2010). It seems reasonable to assume that people with high ILC are more intrinsically satisfied is probably because they believe that the results from their actions in the organization are caused by themselves. When people with high in ILC are successful in their work then they think that success as the manifestation of their ability and feel happier than people with low ILC. Thus, we formulate the following hypothesis concerning the relationship between ILC and IJS.

\section{Equation for the Direct Model}

$$
\text { H1: ILC will affect IJS positively. }
$$

Here,

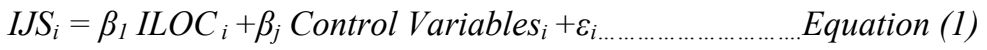

$I J S_{i}=$ Summation of the indicators (see Appendix 1) of IJS

Control Variable $_{i}=$ different control variables

$\varepsilon_{i}=$ error term of the model

\subsection{ILC and Innovative Work Environment}

Some people with specific personality traits tend to expose themselves to intrinsically satisfying works, while others would choose extrinsically satisfying one. Spector (1982) noted that people with a high internal locus of control attempt to align their tasks consistent with themselves. People with high ILC like jobs where they can use their abilities independently. In their study, $\mathrm{Ng}$ et al. (2006) finds that ILC is significantly related to autonomy at work, job feedback, and job challenge among others. Judge et al.'s (2000) finds that there is a significant positive relationship between core self-evaluation, a construct comprised of ILC, self-esteem, self-efficacy and low neuroticism, and job characteristics i.e autonomy, skill variety, task significance, feedback and job challenge and so on. According to Schneider's (1987) Attraction-Selection-Attrition theory ('ASA' hereinafter), people are attracted to or try ot selcte organizations that fit their trait. Organizations also try to recruit individuals whose traits matches with the organizations. After the recruitment when employees finds that their traits did not match the organization culture, they eventually leave the organization. According to the ASA theory, it is reasonable to assume that people with high in ILC tend to choose creative work environments that are characterized by changes and initiatives to do new things. Holland's (1985) personality-job fit theory examined the match between different types of personality traits and job types. For example, people with high self-confidence, ambition, energy, and dominance fit an enterprising type of job. In the same way, in a creative work environment individual needs to be prepared for changes and must take initiative for changes. People with high ILC can match this type of environment. Therefore, we have:

\section{H2 : ILC and creative work environment will be positively related.}

\subsection{Innovative Work Environment and IJS}

Mckinnon et al. (2003) and Zhou et al. (2005) studied the influence of innovation culture and innovative environment on job satisfaction. These studies found a positive significant influence of innovation culture and innovation environment on job satisfaction. More recently, the results of the study of Berson, Oreg, and Dvir (2008) indicated the influence of the organization's innovative culture on job satisfaction. In an innovative work environment, employees can use their creativity that in turn increases their intrinsic satisfaction. Past studies show that 'opportunity for personal control' is positively related to IJS (see, Peyne et al, 1999; Holman, 2002; Spector, 1986; Probst, 2005 ). If employees have more opportunities for personal control, then they have more autonomy and independence to make their own decision. In an innovative work environment, the employees are given the freedom and are encouraged to do the work using their method. These two constructs are similar. Hence, as 
'opportunity for personal control' affects intrinsic job positively, it can be assumed that an innovative work environment will also affect intrinsic satisfaction positively. Therefore, we have:

$\mathrm{H}_{3}$ : Creative environment will affect IJS positively.

\section{Equation for the Mediation Model}

$$
\begin{aligned}
& I J S_{i}=\beta_{1} I L O C_{i}+\beta_{j} \text { Control Variable }{ }_{i}+\varepsilon_{i} \\
& I W E=\beta_{2} I L O C_{i}+\mu_{i} \quad \text { Equation (2) }_{i} \\
& I J S_{i}=\beta_{1} I W E_{i}+\beta_{k} \text { Control Variable } v_{i}+v_{i} \\
& \text { Here,IJS } S_{i}=\text { Summation of the indicators of IJS (see Appendix 1) } \\
& \text { IWE } i=\text { Summation of the indicators of an innovative work environment (see Appendix 1) } \\
& \text { ILOCi= Summation of the indicators of ILC (see Appendix 1) } \\
& \varepsilon_{i}, \mu_{i} \text { and } v_{i}=\text { error term of the model } \\
& \text { Control Variable }=\text { different control variables }
\end{aligned}
$$

\subsection{Innovative Work Environment X ILC Interactive Effect on IJS}

According to the person-environment (P-E) fit theory, those people with higher levels of P-E fit are happier than their counterparts. In an innovative work environment, individuals need to be prepared for changes and must take initiatives to bring forth those changes. People with high ILC match this type of environment well. Therefore, IJS in an innovative work environment will be enhanced for people who are high on ILC.

$H_{4 a}$ : The positive effect of a creative work environment on IJS will be enhanced for people with high ILC.

$H_{4 b}$ : The positive effect of ILC on IJS will also, be enhanced as the level of creative work environment increases.

Equations for the Interaction Model

Here,

$$
I J S_{i}=\beta_{1} I L O C_{i}+\beta_{2} I W E_{i}+\beta_{3} I L O C * C W E+\beta_{j} \text { Control Variable } e_{i}+\varepsilon_{i} \ldots \ldots . . . \text { Equation (3) }
$$

$I J S_{i}=$ Summation of the indicators of IJS(see Appendix 1)

$I W E i=$ Summation of the indicators of an innovative work environment (see Appendix 1)

$I L O C i=$ Summation of the indicators of ILC (see Appendix 1)

$I L O C^{*} C W E=$ Interaction term of ILC and creative work environment.

$\varepsilon_{i,}=$ error term of the model

\subsection{Control Variables}

Sex. Past studies have found that women are intrinsically more satisfied in their jobs than men (see, Clark, 1996, 1997). Thus, we included sex as a control variable in our study.

Age. Past studies have identified a positive linear relationship between age and IJS (see, Rhodes, 1983). Therefore, age was used as a control variable in our study.

Full-time/part-time job. Past research has found mixed result about the relationship between IJS and full-time/ part-time job. Some research shows that there is no significant difference of IJS between full-time and part-time employees (see, Thorsteinson, 2003). Other research shows that part-time employees are intrinsically more satisfied than full-time employees are (see, Clark 1996; Barling \& Gallagher, 1996). Though it could not show us any definite result about the relationship between IJS and type of employment, past research suggests that we include full-time/ part-time as a control.

Workload. Past studies show that workload is positively related to job-related dissatisfaction (see, Lee and Ashforth, 1996; Zellers and Perrewe, 2001; Bakker et al., 2003; Lewing and Dollard, 2003). Hence, we controlled workload in our models.

Tenure. If a person remains in the same organization, he/she may develop loyalty for the organization he/she works for which can influence IJS. Hence, tenure was controlled in our model.

\section{RESEARCH METHODOLOGY}

\subsection{Sample}

The sample consists of 304 employees working in different organizations in Dhaka, Bangladesh. Out of these 304 participants, $90(29.61 \%)$ are females, and $214(70.29 \%)$ are males. The levels of education attained ranged from technical college $(\mathrm{N}=21,6.9 \%)$, undergraduate $(\mathrm{N}=190,62.5 \%)$, masters $(\mathrm{N}=84,27.63 \%)$, doctoral $(\mathrm{N}=6,1.9 \%)$ and to others ( $\mathrm{N}=3,0.9 \%)$. Thirty-four $(11.18 \%)$ individuals work part-time and $270(88.18 \%)$ work fulltime. The type of job consists of management(57,18.75\%), administrative(19,6.25\%), planning $(23,7.57 \%)$, survey and inspection, advertising and public relation, sales $(21,6.91 \%), \operatorname{R} \& \mathrm{D}(26,8.55 \%)$, technology(16,5.26), service $(8,2.63 \%)$, shop or factory owner, professionals $(28,9.21 \%)$, educators $(\mathrm{N}=83,27.30 \%)$, and other jobs $(\mathrm{N}=23$, $7.56 \%$ ). Table 1 shows the correlation matrix of the variables except for sex, fulltime jobs which are dichotomous. Chronbach $\alpha$ for IJS, ILC, creative environment, and life satisfaction are also shown in Table 1. 
Table 1: Correlation Matrix and Chronbach $\alpha$

\begin{tabular}{|c|c|c|c|c|c|c|c|}
\hline & $\begin{array}{c}\alpha \\
\text { (No of Items) }\end{array}$ & 1 & 2 & 3 & 4 & 5 & 6 \\
\hline Innovative Work Environment & $.82(11)$ & 1.00 & & & & & \\
\hline IJS & $.83(9)$ & -.03 & 1.00 & & & & \\
\hline$I L C$ & $.68(8)$ & -.02 & $.26^{* * *}$ & 1.00 & & & \\
\hline Age & - & .01 & $.29 * * *$ & $.12 *$ & 1.00 & & \\
\hline Tennure & - & .01 & $.21 * * *$ & -.01 & $.35 * * *$ & 1.00 & \\
\hline Work Load & - & -.10 & .05 & .01 & -.07 & .07 & 1.00 \\
\hline
\end{tabular}

\subsection{Measurement of the Variables}

Creative Work Environment For measuring the creative work environment, the innovation dimension of Moos's (1994) Work Environment Scale was used. We used nine items (see, Appendix 1), each presented with five response alternatives from 1 (Strongly disagree), 2 (Disagree), 3 (Neutral), 4 (Agree), and 5 (Strongly agree).

IJS For measuring IJS we used eleven items (see, Appendix 1) of the Minnesota Satisfaction Questionnaire. We presented the items with five alternatives for each - 1 (Very Dissatisfied), 2 (Dissatisfied), 3 (Neither dissatisfied nor satisfied), 4 (Satisfied), and 5 (Very satisfied).

ILC For measuring ILC we used the internal dimension of Levenson's (1973) Internal, Powerful Others, and Chance (IPC) scale. There were eight items (see, Appendix 1) with six alternatives for each - 1 (Strongly disagree), 2 (Disagree somewhat), 3 (Disagree slightly), 4 (Agree slightly), 5 (Agree somewhat), and 6 (Strongly agree).

Control Variables The respondents were asked to indicate their tenure in years and months. We then converted those into a single unit of months. The workload was recorded by asking how many hours the respondents work in a typical week. Age was measured in years.

We used the Ordinary Least Square (OLS) method for estimating the parameters the direct and interaction models. For estimating the parameters of the mediation model Three-Stage Least Square method was used in the study.

\section{FINDINGS}

Table-2 reports the estimates of the coefficients for the direct models. Hypothesis 1 concerned the direct effect of ILC on IJS. As shown in Table 2, the path coefficient was 0.33 in Model 1a and 1b, .35 in Model 1c and all are statistically significant $(p<.001)$. Hypothesis 2 and 3 proposed the meditational relationship between ILC, creative environment, and IJS. As expected the path from ILC to the creative environment was .05 and significant $(p<. .05)$ and that from creative work environment to intrinsic locus of control was 3.03 and significant $(p<.000)$. However, the path from ILC to IJS after controlling for creative work environment became smaller i.e $0.12(p<.000)$ than that of the direct models. Therefore, there is a partial mediation in of innovative work environment in the relationship between ILC and IJS.

Table 2: Direct Model

\begin{tabular}{llll}
\hline & Model 1a & Model 1b & Model1c \\
\hline ILC & $.33^{* * *}$ & $.33^{* * *}$ & $.35^{* * *}$ \\
Innovative Environment & - & -.11 & -.16 \\
Age & $.15^{* * *}$ & $.15^{* * *}$ & $0.11^{* *}$ \\
Sex & .97 & -.95 & -1.15 \\
Full-time & -.58 & -.59 & -1.33 \\
Tennure & $.088^{* *}$ & $.088^{* *}$ & $0.071^{*}$ \\
Workload & .024 & .022 & .017 \\
Education & $.85^{*}$ & $.88^{*}$ & 0.844 \\
Management & - & - & $4.75^{* * *}$ \\
Admin & - & - & -1.36 \\
Planning & - & - & 2.65 \\
Sales & - & - & 0.95 \\
R\&D & - & - & 1.94 \\
Technology & - & - & 2.25 \\
Service & - & - & 0.66 \\
Professionals & - & - & $4.41^{* * *}$ \\
Constant & $16.58^{* * *}$ & $19.22^{* * *}$ & $20.04 * *$ \\
\hline Note: ${ }^{*} p<.05, * * p<.01, * * * p<.001$ & &
\end{tabular}


Table 3: Mediation Model

\begin{tabular}{lcc}
\hline & Coefficient & $\mathbf{Z}$ \\
\hline IJS $\leftarrow$ ILOC & $.12^{* * *}$ & 2.68 \\
ILC (ILOC) & $.036^{*}$ & 2.05 \\
Age & .17 & 0.42 \\
Sex & -.056 & -0.10 \\
Fulltime & .017 & 1.12 \\
Tennur & -.016 & -1.02 \\
Work load & .45 & 1.60 \\
Education & $32.43 * * *$ & 15.93 \\
Constant & & \\
Innovative Work Env $\leftarrow$ ILOC & $.054^{*}$ & 2.22 \\
ILC (ILOC) & .48 & 1.06 \\
Rnd & -.12 & -0.39 \\
Mgt & .63 & 1.44 \\
Prof & $21.36^{* * *}$ & 25.71 \\
Constant & & \\
IJS $\leftarrow$ Innovative Work Env. & $3.03^{* * *}$ & 3.04 \\
Innovative Work Env. & -1.56 & -1.56 \\
R\&D & .82 & 1.26 \\
Management & $-2.11^{*}$ & -2.00 \\
Professionals & $-30.80^{* * *}$ & -1.33 \\
Constant & & \\
\hline
\end{tabular}

Note: $* p<.05, * * p<.01, * * * p<. .001$

Hypothesis $4 \mathrm{a}$ and $4 \mathrm{~b}$ proposed the interaction effect of ILC and the innovative work environment on IJS. As expected a positive significant effect for the path from the interaction term to IJS, it was significant $(0.06, p$ $=.02$; see, Table 4). However, the effect of ILC to IJS became insignificant in the interaction model $(-1.14, \mathrm{P}=.09)$.

Table 4: Interaction Model

\begin{tabular}{lccc}
\hline & Coefficient & Z & P values \\
\hline ILC & -1.14 & -1.67 & 0.096 \\
I. Locus of Control*Innovative Environment & .065 & 2.20 & 0.029 \\
Innovative Environment & -2.28 & -2.34 & 0.020 \\
Management & 4.47 & 2.88 & 0.004 \\
Admin & -1.43 & -0.79 & 0.433 \\
Planning & 2.30 & 1.31 & 0.192 \\
Sales & 0.65 & 0.36 & 0.716 \\
R\&D & 2.11 & 1.25 & 0.212 \\
Technology & 1.93 & 0.99 & 0.321 \\
Service & 0.38 & 0.16 & 0.870 \\
Professionals & 4.28 & 2.60 & 0.010 \\
Educators & 3.20 & 2.24 & 0.026 \\
Age & 0.129 & 3.11 & 0.002 \\
Sex & -1.31 & -1.50 & 0.134 \\
Full-time & -1.34 & -1.00 & 0.318 \\
Tennur & 0.075 & 2.16 & 0.032 \\
Workload & 0.026 & 1.21 & 0.229 \\
Educatin & 0.88 & 1.97 & 0.049 \\
Constant & 68.45 & 3.02 & 0.003 \\
\hline
\end{tabular}

Note: $* p<.05, * * p<.01, * * * p<. .001$

\section{DISCUSSION}

Since Rotter (1954) developed a psychological construct, locus of control, it has been studied widely as an important human personality trait and its relationship with job satisfaction. But little attention has been paid to the identification of direct, indict, and interaction effect of ILC on IJS. Moreover, the creative work environment has been studied widely but its direct and interactional effects on IJS have not been examined yet.

The present study proposed three models that showed ILC and creative environment as direct, indirect, interaction antecedents of IJS. We hypothesized that ILC can influence IJS positively. After controlling for sex, full-time/ part-time job status, tenure, and workload, the data suggested that the levels of subjects' IJS were 
predictable from the level of ILC. We also hypothesized that the relationship between ILC and IJS would be mediated by a creative work environment. The data showed that there was a partial mediation effect of the creative work environment on the relationship between ILC and IJS. Moreover, we also hypothesized that the ILC and creative work environment would have an interactional effect on IJS after controlling for the main effects and other control variables. Our data showed a significant influence on the interaction term on IJS.

The implication of the study is that management should consider the importance of a creative work environment and ILC for increasing intrinsic satisfaction. Management can create an organization with intrinsically satisfied employees by recruiting individuals who are high in ILC. Moreover, management can create a creative work environment in the organization that will attract people who are high on ILC and thus can keep the level of the IJS of the employees high.

The results presented in this study are a nice starting point for future research, but it is important to discuss the study's limitations. One limitation of the study is that the reported ILC, creative work environment, and IJS were subjective measures by the employees. Self-reported measures of constructs may cause bias in the measurement. Third-party evaluation (immediate boos, peer) of these constructs would probably give more accurate results.

Another limitation of the study is that the data were collected just at one point in time, assuming that the constructs were stable over time. But this assumption is weak. Though past studies have shown that personality traits and job satisfaction are stable over time, the correlation between two points of time is not one (i.e. $\left.r_{t 1, t 2} \neq 1\right)$. Moreover, an organization's work environment is dynamic and changes over time. Future studies should collect data at multiple points in time to examine the long-term stability of the effects of intrinsic locus of control and creative environment on IJS.

\section{References}

Bakker, A. B., Demerouti, E., De Boer, E., \& Schaufeli, W. (2003). Job demand and job resources as predictors of absence duration and frequency. Journal of Vocational Behavior, 62, 341-356.

Barling, J., \& Gallagher, D. G. (1996). Part-time employment. In C.L. Cooper \& I. T Robertson (Eds), International review of industrial and organizational psychology (pp. 243-277). Chichester, UK: Wiley.

Bennassi, V. A., Sweeney, P. D., \& Dufour, C.L. (1988). Is there a relationship between locus of control and depression. Journal of Abnormal Psychology, 97, 357-367.

Berson, Y., Oreg, S., \& Dvir, T. (2008). CEO values, organizational culture and firm outcomes. Journal of Organizational Behavior, 29, 615-633.

Clark, A. E. (1996). Job satisfaction in Britain. British Journal of Industrial Relations, 34, 189- 217.

Clark, A. E. (1997). Job satisfaction and gender: Why are women so happy at work? Labour Economics, 4, 341 372.

Diener, E., Emmons, R. A., Larsen, R. J., \& Griffin, S. (1985). The Satisfaction with Life Scale. Journal of Personality Assessment, 49, 71-75.

Holman, D. (2002). Employee well-being in call centres. Human Resource Management Journal, 12, 35-50.

Iffaldano, M. T., \& Muchinsky, P. M. (1985). Job satisfaction and job performance: A meta analysis. Psychology Bulletin, 97, 252-273.

Joreskog, K.G., \& Sorbom, D. (1996). LISREL 8:User's Reference Guide, Chicago: Scientific Software International.

Judge, T. A., \& Bono, J. E. (2001). Relationship of core self-evaluations traits-self-esteem, generalized self efficacy, locus of control, and emotional stability - with job satisfaction and job performance: a meta-analysis. Journal of Applied Psychology, 86, 80-92.

Judge, T.A., Bono, J.E., \& Locke, E .A. (2000). Personality and job satisfaction: the mediating role of job characteristics. Journal of Applied Psychology, 85,237-249

Kinicki, A. J. Mckee-Ryan, F.M. Schriesheim, C. A. \& Carson, K. P. (2002). Assessing the construct validity of the Job Descriptive Index: A review and meta analysis. Journal of Applied Psychology, 87, 1-22.

Lee, R.T., \& Ashforth, B.E. (1996). A meta- analytic examination of the correlations of the three dimensions of job burnout. Journal of Applied Psychology, 81, 123-133.

Levenson, H. (1973). Multidimensional locus of control in psychiatric patients. Journal of Consulting and Clinical Psychology, 41, 397-404.

Lewig, K.A., \& Dollard M.F. (2003). Emotional dissonance, emotional exhaustion and job satisfaction in call centre workers. European Journal of Work and Organizational Psychology, 12, 366-392.

McGinnis,, E. Nordholm, L. A., Ward, C. D., \& Bhanthumnavin D. L. (1974). Sex and cultural differences in perceived locus of control among students of five countries. Journal of Consulting and Clinical Psychology, 42(3), 451-455

McKinnon, J. L., Harrison, G. L., Chow C.W., \& Wu, A. (2003). Organizational Culture: Association with commitment, job satisfaction, propensity to remain, and information sharing in Taiwan. International Journal 
of Business Studies, 11, 25.

Moos, H. R. (1994). Work Environment Scale Manual: Development, Application, Research, Third Edition, Consultant Psychologists Press, Inc.

Muthén, L.K., \& Muthén, B.O. (1998-2007). Mplus User’s Guide. Fifth Edition. Los Angeles, CA: Muthén \& Muthén.

NG, W.H., Thomas, Sorensen L. K., \& Eby T. L. (2006). Locus of control: a meta-analysis. Journal of Organizational Behavior, 27, 1057-1087.

Payne, R. L., Wall T.D., Borrill, C., \& Carter, A. (1999). Strain as a moderator of the relationship between work characteristics and work attitudes. Journal of Occupational Health Psychology, 4, 3-14.

Probst, T.M. (2005). Countering the negative effects of job insecurity through participative decision making: Lessons from the demand-control model. Journal of Occupational Health Psychology, 10, 320-329.

Rhodes, S. R. (1983). Age-related difference in work attitudes and behavior: A review and conceptual analysis. Psychology Bulletin, 93, 328-367.

Sagie, A., Birati A. \& Tziner A. (2002). Assessing the Cost of Behavioral and Psychological withdrawal: A New Model and an Empirical Illustration. Applied Psychology: An International Review, 2002, 51(1), 67-89

Schneider, B. (1987). The people make the place. Personnel Psychology, 40, 437-453.

Schwab, D. P \& Heneman, H. G. (1977). Age and satisfaction with dimension of work. Journal of Vocational Behavior, 10, 212-220.

Spector, P.E. (1982). Behavior in organization as a function of employees' locus of control. Psychological Bulletin, 91, 482-497.

Spector, P.E. (1986). Perceived control by employees: A meta-analysis of studies concerning autonomy and participation at work. Human Relations, 39, 1005-1016.

Spector, P.E, Zapf, D., Chen, P. Y., \& Frese, M. (2000). Why negative affectivity should not be controlled in job stress research: Don't throw out the baby with the bath water. Journal of Organizational Behavior, 21, 7995.

Tareq M., Watanabe S., Kanazawa Y. (2010) Mapping a Psychological Process Underlying the Causal Link from Locus of Control to Intrinsic Job Satisfaction: The Mediating Role of Perceived Work Environment, Japanese Journal of Administrative Science, Volume 23, No.1

Thorsteinson, T. J. (2003). Job attitudes of full- and part-time employees: A meta- analytic review. Journal of Occupational and Organizational Psychology, 76, 151-177.

Zellars, K. L., \& Perrewe P.L. (2001). Affective personality and the content of emotional social support: Coping in organizations. Journal of Applied Psychology, 86, 459-467.

Zhou, K.Z., Gao, G. Y., Yang, Z., \& Zhou N. (2005). Developing strategic orientation in China: Antecedents and consequences of market and innovation orientation. Journal of Business Research, 58, 1049-1058.

\section{APPENDIX 1}

Intrinsic Job Satisfaction Scale

\begin{tabular}{ll}
\hline Item No. & \multicolumn{1}{c}{ Items } \\
\hline IJS1 & Being able to keep busy all the time. \\
IJS2 & The chance to work alone on the job. \\
IJS3 & The chance to do different things from time to time. \\
IJS4 & The chance to be somebody in the community. \\
IJS5 & Being able to do things that don't go against my conscience. \\
IJS6 & The chance to do things for others. \\
IJS7 & The chance to tell people what to do. \\
IJS8 & The chance to do something that makes use of my abilities. \\
IJS9 & The freedom to use my own judgment \\
IJS10 & The chance to try my own methods of doing the job. \\
IJS11 & The feeling of accomplishment I get from the job. \\
\hline & $\quad$ Internal Locus of Control Scale \\
\hline Item No. & \\
ILOC1 & \\
ILOC2 & When I make plans, I am almost certain to make them work. \\
ILOC3 & How many friends I have depends on how nice a person I am. \\
ILOC4 & I can pretty much determine what will happen in my life. \\
ILOC5 & I am usually able to protect my personal interests. \\
ILOC6 & When I get what I want, it's usually because I worked hard for it. \\
ILOC7 & My life is determined by my own actions. \\
ILOC8 &
\end{tabular}




\section{Innovative Work Environment Scale}

\begin{tabular}{ll}
\hline Item No. & \multicolumn{1}{c}{ Items } \\
\hline IWE1 & Doing things in a different way is valued. \\
IWE2 & New and different ideas are always being tried out. \\
IWE3 & The place would be one of the first to try out a new idea. \\
IWE4 & Variety and change are not particularly important. \\
IWE5 & The same methods have been used for quite a long time. \\
IWE6 & New approaches to things are rarely tried. \\
IWE7 & Things tend to stay just about the same. \\
IWE8 & There is a fresh, novel atmosphere about the place. \\
IWE9 & Things always seem to be changing. \\
\hline
\end{tabular}

